\title{
Eestirootsi keele prosoodia tunnusjooni
}

\author{
Eva Liina Asu \\ Tartu Ülikooli eesti ja üldkeeleteaduse instituudi foneetika vanemteadur \\ eva.liina.asu-garcia@ut.ee
}

\begin{abstract}
Teesid: Eestirootsi ehk rannarootsi keelt räägiti Eesti läänepoolsetel rannikualadel ja saartel laialdaselt kuni Teise maailmasõjani, mil enamik eestirootslastest emigreerus Rootsi. Praeguseks on see rootsi keele murre säilinud ainult umbes paarisaja eaka Rootsis elava kõneleja omavahelises keelekasutuses. Artiklis vaadeldakse lähemalt eestirootsi keele prosoodia tunnusjooni, keskendudes sõnatoonidele ja rütmile. Sõnatoonide realiseerumise võrdlus kahesilbilistes sõnades näitab, et eestirootsi (nagu ka soomerootsi) keeles ei esine riigirootsi keelele nii iseloomulikku sõnatoonide vastandust. Eestirootsi, riigirootsi ja eesti keele rütmi võrdlusest selgub aga, et erinevalt püstitatud hüpoteesist, mille järgi eestirootsi võiks rütmiliste näitajate poolest paigutuda riigirootsi ja eesti keele vahele, on eestirootsi rütm oma kestusnäitajate poolest siiski väga sarnane riigirootsi rütmile.
\end{abstract}

Märksõnad: eestirootsi murded, prosoodia, rootsi keel, rütm, sõnatoonid

\section{Sissejuhatus}

Käesolevas artiklis kirjeldatakse mõningaid eestirootsi prosoodia tunnusjooni, mida on akustilis-foneetiliste meetodite abil uuritud projekti "Eestirootsi keele struktuur" (ESST - Estlandssvenskans språkstruktur) raames. Projekt käivitus 2013. aastal ja selle aja jooksul on läbi viidud mitmeid uurimusi nii eestirootsi foneetikast (nt Schötz \& Nolan et al. 2014; Asu \& Nolan et al. 2015 frikatiividest; Ewald \& Asu et al. 2017 vokaalidest) kui ka süntaksist (nt Rosenkvist 2015, 2016; Andréasson 2016). Siinkohal antakse ülevaade peamiselt kahes varem avaldatud artiklis esitatud tulemustest eestirootsi sõnatoonide (Schötz \& Asu 2015) ja rütmi (Asu \& Nolan et al. 2017) kohta. Kuna puuduvad varasemad akustilised uurimused eestirootsi foneetikast ja on olemas vaid kuuldelisel alusel põhinevaid fonoloogilisi kirjeldusi (nt Danell 1905-1934; Tiberg 1962; Lagman 1979), siis pakuvad need uuemad tööd esimest korda foneetilistele mõõtmistele 
tuginevaid teadmisi eestirootsi murrete akustikast ning võimaldavad kõrvutada eestirootsi häälduse aspekte teiste rootsi keele murrete ning muude keeltega.

Rootsi keelt on Eesti läänepoolsetel rannikualadel ja saartel räägitud juba alates 13. sajandist või isegi veel varem. Esimeseks dokumendiks, milles rootslasi mainitakse, on Haapsalu linnaõigus aastast 1294. Tuginedes ajaloolistele allikatele väidab Jonathan Lindström (2015), et esimesed rootsi talupoegadest asunikud saabusid Eestisse 1206. aastal seoses Lundi peapiiskop Andreas Sunessoni korraldatud Taani-Rootsi ristikäiguga, nad olid pärit Ölandilt ja asusid elama Vormsi saarele. Viimaste arheoloogiliste andmete põhjal on alust arvata, et pidev skandinaavlaste asustus võis Eesti rannikul tekkida aga juba oluliselt varem ehk vanema rauaaja lõpus (Markus 2004). Eestirootslaste varasemast asustusest Eesti aladel annab lühiülevaate Evi Juhkami (1992) Keeles ja Kirjanduses ilmunud artikkel.

Aegade jooksul on rootslasi Eesti aladele sisse rännanud nii erinevatest Rootsi piirkondadest kui ka rootsikeelsetelt aladelt Soomes (eelkõige Nylandist), tuues endaga kaasa mitmesuguseid rootsi murdeid. Eestirootsi murrete vanim kihistus pärineb ajavahemikust 1225-1375, mida rootsi keeleajaloos kutsutakse klassikaliseks vanarootsi perioodiks (Tiberg 1962). Tänu pikaaegsele suhtelisele eraldatusele riigirootsi ja soomerootsi aladest on eestirootsi keeles säilinud mitmed arhailised murdejooned, mis muudest rootsi murretest on nüüdseks kadunud, nt puudub eestirootsis velaarsete klusiilide frikatiivistumine eesvo-

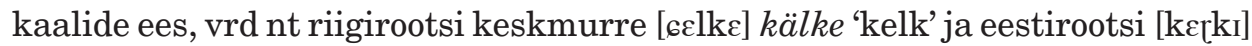
(Asu \& Ewald et al. 2015). Eestirootsi murretes on säilinud vanaskandinaavia keelest pärinevad diftongid (Lagman 1979), mis enamikust idaskandinaavia murretest kadusid 10. sajandil taani keeles alanud häälikumuutuse tagajärjel, vrd nt riigirootsi keskmurre ben 'jalg' ja eestirootsi /bain/, riigirootsi blöt 'märg' ja eestirootsi /blaut/ (Ewald 2016).

Eestirootsi puhul on kindlasti iseloomulik ka see, et eestirootsi keel ei moodusta ühte enam-vähem ühtset murret, vaid jaotub mitmeks väiksemaks murrakuks, mis tänu suhtelisele isoleeritusele üksteisest on hästi eristatavate murdejoontega. Eestirootsi ühiskeelest (rootsi k högspråksvarianten) saab rääkida alles seoses koolisüsteemi arenguga 1800. aastate lõpus ja 1900. aastate alguses (Lagman 1979: 7). Joonisel 1 on toodud Eesti lääneranniku ja saarte kaart 1930. aastatest, millel on tumedamalt märgitud rootsikeelsed piirkonnad. Eelkõige häälduse ja sõnavara järgi võib eestirootsi murdeala jagada neljaks piirkonnaks (Lagman 1979: 5). Neist kõige suuremaks on Noarootsi-RiguldiVormsi (Nuckö-Rickul-Ormsö), mille alla kuulub ka Osmussaare (Odensholm) murrak ja varasemalt Hiiumaal kõneldud murrak koos Gammalsvenskby murrakuga Ukrainas. Suuruselt teiseks murderühmaks on Pakri-Kurkse-Vihterpa- 
Joonis 1. Eestirootsi alad 1930. aastatel. Kaardi on joonistanud Richard Aman (Lagman 1979: 2).

lu (Rågöarna-Korkis-Vippal), millele järgnevad Ruhnu (Runö) ja Naissaare (Nargö) murrak. Eestirootsi murdeid on tugevalt mõjutanud eesti keel, millega eri piirkondade kõnelejad puutusid kokku erineval määral, nt

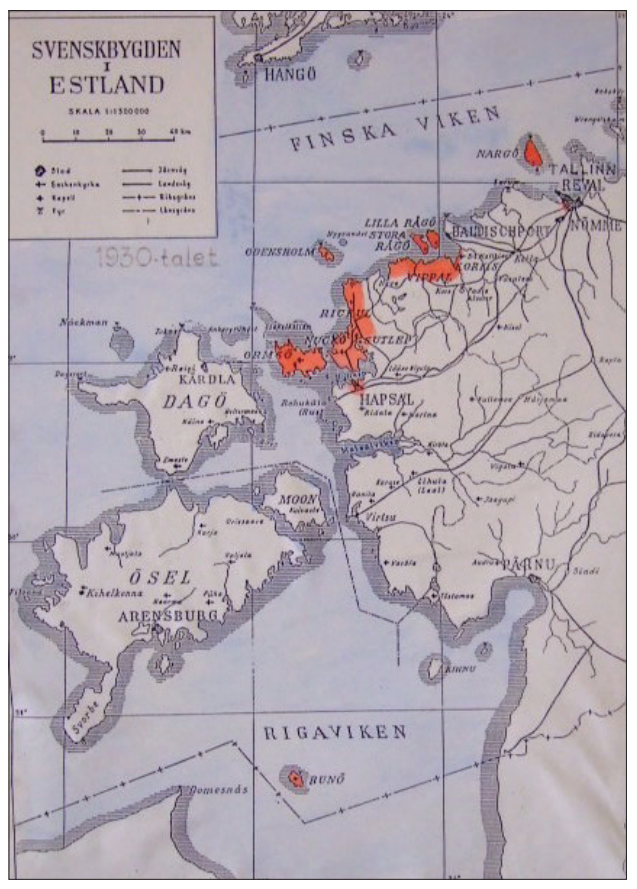
olid varemalt sellised väikesaared nagu Vormsi, Ruhnu, Osmussaar ja Pakri saared ning Riguldi piirkond täiesti rootsikeelsed ja seal oli kokkupuuteid eesti keelega ka vähem, samal ajal kui Naissaarel ning Kurksi ja Vihterpalu piirkondades elasid rootslased ja eestlased kõrvuti ning ka eesti keele mõju oli seal suurem. Rootsi ja eesti keele kontaktid on aga kahtlemata kaasa toonud mõjusid mõlemal suunal (Eliasson 2008: 2051-2054). Eestirootsi mõjusid eesti keele murretele on põhjalikumalt uurinud Paul Ariste (1931, 1933, 1981) ja Evi Juhkam (1983, 1998, 2000, 2009).

1934. aasta rahvaloenduse järgi elas Eestis 7641 rootslast, mis moodustas 0,7\% kogurahvastikust. Väärib mainimist, et rannarootslastele oli juba Eesti esimese iseseisvuse ajal tagatud oma kultuurautonoomia. Enamik rannarootslasi asus aga ümber või põgenes aastail 1943-1944 uue Nõukogude okupatsiooni kartuses Rootsi. Eestisse jäi umbes 1500 eestirootslast (Juhkam 1992: 399). 1970. aasta rahvaloenduse järgi oli Eestis 435 rootslast. Tänapäeval on eestirootsi murrete oskajaid alles jäänud väga vähe, Eestis on neist vaid mõned üksikud. Valdav osa eestirootsi murrete oskajaist elab Rootsis peamiselt Stockholmis ja selle ümbruses ning on suhteliselt kõrges eas, kuuludes Eestist Teise maailmasõja ajal lapsena lahkunute põlvkonda. Seegi asjaolu on olnud üks olulisi tegureid, mis ajendas uurima eestirootsi keelt just praegu, mil veel on alles selle hääbumisele määratud rootsi murde kõnelejaid. 


\section{Sõnatoonid}

Kõige tähtsamaks rootsi keelt iseloomustavaks prosoodiliseks tunnusjooneks on kahtlemata sõnatoonid ehk siis kahe sõnatooni (aktsent 1 ehk akuutaktsendi (rootsi k akut) ja aktsent 2 ehk graavaktsendi (rootsi k grav)) vastandus sellistes sõnades nagu nt anden (aktsent 1: /'anden/ 'part', aktsent 2: / 'ànden/ 'vaim'). Foneetiliselt väljenduvad sõnatoonid põhitoonikontuuri tippude erinevas ajastuses: akuutaktsendiga sõnades on põhitoonitipp varasem kui graavaktsendiga sõnades. Sõnatoonide realiseerumine sõltub väga suurel määral kõneleja päritolupiirkonnast, seda variatiivsust on kirjeldatud mitmes rootsi keele prosoodilises tüpoloogias (Gårding 1977; Riad 2006; Bruce 2007). Joonisel 2 on toodud Eva Gårdingi (1977) rootsi keele sõnatoonide tüpoloogia, mis skemaatiliselt näitab, kuidas toonikontuur realiseerub lausefookuselistes kahesilbilistes akuut- ja graavaktsendiga sõnades.

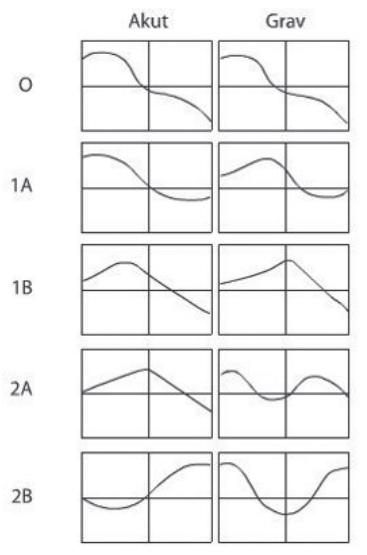

Joonis 2. Rootsi sõnatoonide skemaatilised kontuurid lausefookuselistes $k a h e s i l b i l i s t e s$ akuutaktsendi (rootsi $k$ akut) ja graavaktsendiga (rootsi $k$ grav) sõnades (Gårding 1977).

Gruppi 0 kuuluvad murded, milles akuutaktsendi ja graavaktsendi realiseerumisel erinevust ei ole, nt soomerootsi keel. Soomerootsis esineb sõnatoonide vastandust vaid Lääne-Nylandi murdes (Selenius 1972, 1978). Vaadeldes aga laiemalt kogu Skandinaavia keeli rääkivat piirkonda, nähtub, et tüüpiliselt ei esine sõnatoonide vastandust selle piirkonna äärealadel, sh fääri ja islandi keeles ning põhjarootsi, lõunataani ja Finnmarki norra ning mõnes läänenorra murdes Bergeni ümbruses (Riad 2006). Gruppides 1A ja 1B vastanduvad varase ja hilise põhitoonitipuga kontuurid (varasem on tipp aktsent 1 sõnades kui 
aktsent 2 sõnades) ning gruppides $2 \mathrm{~A}$ ja $2 \mathrm{~B}$ on vastandus ühetipuliste (akuut) ja kahetipuliste (graavis) kontuuride vahel.

Traditsiooniliselt on eestirootsi keeles kirjeldatud ainult ühe sõnatooni olemasolu (nt Haugen 1976). Arvatakse, et algne kontrast akuutaktsendi ja graavaktsendi vahel oli siiski eestirootsi keeles suure tõenäosusega olemas (Liberman 1982: 201), kuigi Lagman (1979: 39) kahtleb, kas see esines kõigis eestirootsi murretes. Nagu soomerootsi keeleski, kus sõnatoonide vastandus kadus ilmselt soome keele mõjul, kadus eestirootsi keelest see eesti keele mõjul (Lagman 1979: 38). Selline oletus tundub tõenäoline, arvestades olulist eesti keele mõju eestirootsi häälikusüsteemile (Danell 1905-1934). Samas on ka võimalik, et sõnatoonide vastandust pole eestirootsi keeles kunagi esinenudki analoogselt fääri ja islandi keelele, kus see nähtavasti kunagi ei tekkinud (Bye 2004). Seda võiks toetada ka nn vanaskandinaavia hüpotees, mille järgi arenes Skandinaavia keeltes tonaalne opositsioon alles 1000-1200 AD või isegi veel hiljem (Bye 2004: 10).

Susanne Schötzi ja Eva Liina Asu (2015) uurimuse eesmärk oli kindlaks teha, kuidas täpselt realiseeruvad eestirootsi sõnatoonid akustiliselt. Arvestades varasemaid töid ja üldist Skandinaavia keelte tüpoloogiat, oletasime, et eestirootsis sõnatoonide vastandust kahesilbilistes lihtsõnades ei esine. Siiski pole võimatu, et kunagisest sõnatoonide vastandusest on jäänud mingeid jälgi, nagu näiteks soomerootsi Närpe murdes (Svärd 2001), kus hoolimata fonoloogilise opositsiooni puudumisest esineb süstemaatiline erinevus aktsent 1 ja aktsent 2 sõnade põhitoonikontuuride realiseerumises.

\section{Materjal}

Katse andmestiku moodustasid nii etteloetud kui ka poolspontaanselt esitatud testsõnad. Etteloetud materjal koosnes kümnest kahesilbilisest sõnast, mis enamikus rootsi murretes moodustavad minimaalpaarid: /'anden/ 'part' - /'ànden/ 'vaim', /'ju:den/ 'helid' - /'jùden/ 'juut', /'po:len/ 'Poola' - /'pò:len/ 'vai', /'tanken/ 'tank' - /'tànken/ 'mõte' ja /'tomten/ 'ehituskrunt' - /'tòmten/ 'päkapikk'. Kõigis sõnades on rõhk esimesel silbil. Testsõnad olid paigutatud raamlausesse lauserõhulisse positsiooni: Jag sade __åtur ('Ma ütlesin __ veel kord'). Materjal salvestati kuue keelejuhi poolt (3 naist ja 3 meest), kes olid pärit Noarootsi-Riguldi-Vormsi murdealalt. Poolspontaanse kõne lindistamiseks kasutati pilte, milledel olid illustreeritud samad kümme sõna. Lisaks lindistati osadelt keelejuhtidelt veel sõnad /' tèm:en/ 'pöial' ja /'skal:en/ 'haukumine'. Iga lauset ja sõna paluti hääldada vaid ühe korra. Analüüsist jäeti välja need sõnad, mis ei olnud loetud lausetes lauserõhulises positsioonis, mis tähendab, et testsõnade arv keelejuhiti varieerus. Kokku analüüsisime kuuelt keelejuhilt 20 
etteloetud akuutaktsendi ja 31 graavaktsendiga sõna ning 40 poolspontaanset akuutaktsendi ja 43 graavaktsendiga sõna.

Põhitoonianalüüsiks kasutati sama meetodit, mida on varem rakendatud rootsi keele prosoodilise variatsiooni uurimiseks (vt Schötz \& Bruce et al. 2012; Schötz \& Asu 2013). Programmiga Praat (Boersma \& Weenink 2015) märgendati manuaalselt iga vokaali algus. Et hõlbustada kõnelejate võrdlemist, normaliseeriti põhitoonikontuurid, kasutades pooltoone (iga kõneleja miinimum võrdsustati 0 pooltooniga). Kummagi kõnestiili keskmiste põhitoonikontuuride arvutamiseks võeti igas testsõnas keskmise põhitooni väärtused sajas üksteisest võrdse kaugusega punktis.

\section{Tulemused}

Joonisel 3 on näha aktsent 1 ja aktsent 2 sõnade keskmised põhitoonikontuurid loetud ja poolspontaansetes sõnades.
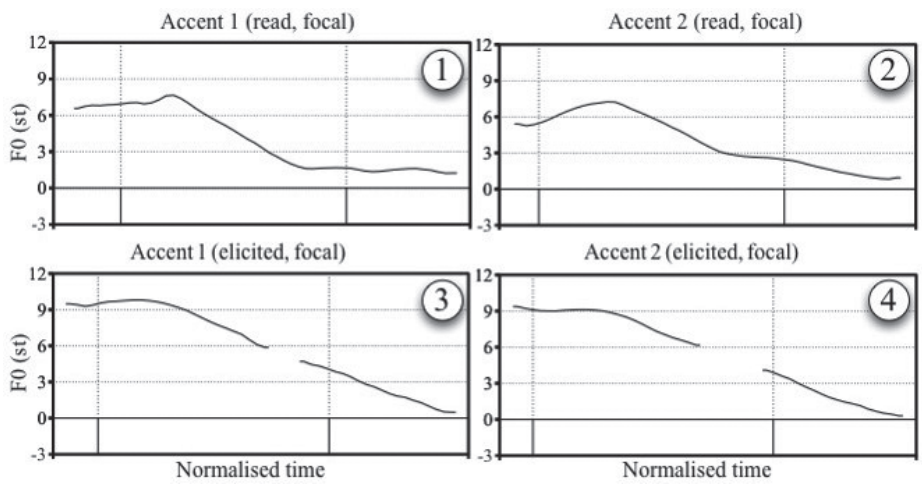

Joonis 3. Keskmised põhitoonikontuurid loetud (paneelid 1-2) ja poolspontaansetes (paneelid 3-4) aktsent 1 ja aktsent 2 sõnades (vertikaalsed jooned märgivad vokaalide algust) (Schötz \& Asu 2015).

Loetud sõnades (paneelid 1-2) on põhitoonikontuur sõna alguses kergelt tõusev ja toonikontuuri tipp paikneb umbes esimesel kolmandikul esimese vokaali sees, millele järgneb langus ja madal platoo enne järgmise vokaali algust. Poolspontaansetes sõnades (paneelid 3-4) algab põhitoonikontuur kõrge platooga, millele järgneb langus ülejäänud sõna jooksul. Kummaski kõnestiilis ei ole aga sõnatoonide realiseerumise vahel erinevust: kõik põhitoonikontuurid on ühetipulised ning nii aktsent 1 kui ka aktsent 2 sõnades asub põhitoonitipp suhteliselt vara esimese vokaali sees. 


\section{Kokkuvõte}

Susanne Schötzi ja Eva Liina Asu (2015) uurimus näitas, et eestirootsi keeles ei esine sõnatoonide vastandust: aktsent 1 ja aktsent 2 sõnade toonikontuurid on ühesugused. Selline tulemus oli igati ootuspärane ja sobitub varasemate eestirootsi murrete kirjeldustega ning laiema Skandinaavia sõnatoonide tüpoloogiaga, kus sõnatoonide vastandust ei esine Skandinaavia keeli rääkiva piirkonna äärealadel. Seega võiks lisada ka eestirootsi murde Eva Gårdingi (1977) rootsi keele prosoodia tüpoloogias soomerootsi kõrvale 0-tüüpi murrete rühma. Antud uurimuses kasutati ainult Noarootsi-Riguldi-Vormsi murdetaustaga keelejuhte, aga arvestades eestirootsi murrete vahelisi märgatavaid erinevusi (Lagman 1979), võivad tonaalsed mustrid teistes murretes olla erinevad, mis siiski tundub vähe tõenäoline.

\section{Rütm}

Teiseks eestirootsi prosoodia aspektiks, mida eestirootsi keele struktuuri projekti raames on uuritud, on rütm (Asu \& Nolan et al. 2017). Selle uurimuse lähtepunktiks oli Edvin Lagmani tähelepanek eestirootsi omapärasest rütmist, mis seisneb lauserõhkude suhteliselt ühtlases jaotumises võrreldes riigirootsi keelega (Lagman 1979: 21-22). Sellele tuginedes oletasime, et kontaktide tõttu eesti keelega paigutub eestirootsi murre oma rütmiliste näitajate poolest riigirootsi ja eesti keele vahele.

\section{Rütmi tüpoloogia}

Keeleteadlased on juba ammu olnud huvitatud keelte klassifitseerimisest nende rütmi järgi. On teada, et kõne rütmi annavad eri tasanditel edasi mitmed foneetilised tunnused (Bruce 1998), aga enamasti on rütmi kirjeldatud siiski ajateljel, s.t on mõõdetud vokaalide, konsonantide või silpide kestust üksteise suhtes.

Rütmilise tüpoloogia järgi jaotatakse keeli tavaliselt rõhuajastuskeelteks ja silbiajastuskeelteks. Selline kahene jaotus põhineb samuti kõne ajalistel tunnustel ning on seotud isokroonia ehk samakestuslikkuse mõistega (Pike 1945), mis viitab sellele, et prosoodilise süsteemi keskse üksuse (nt silbi) kestus hoitakse sama pikana. Isokroonia ei ole absoluutne mõiste, vaid pigem püüdlus mingite üksuste sarnasele pikkusele (vt lähemalt Asu \& Lippus et al. 2016: 30).

Rõhuajastuskeeltes (nt inglise keel) on rütm seotud rõhuga. Sõnarõhk on liikuv, rõhulised üksused on pikad ja rõhutud lühikesed (esineb vokaalide 
redutseerumine) ning rõhulised silbid esinevad ühtlaste intervallide tagant. Silbiajastuskeeltes, milleks on nt prantsuse ja hispaania keel, on keskseks üksuseks silp. Sõnarõhk paikneb mingil kindlal silbil ning silbid on enam-vähem sama kestusega, mis tähendab, et rõhuliste ja rõhutute silpide vahel on väga väike erinevus.

Paraku on tulnud nentida, et keeli ei ole võimalik nende kahe tüübi vahel selgepiiriliselt jagada, kuna esineb liiga palju varieerumist. Alates 1990. aastatest on välja töötatud erinevaid matemaatilisi mudeleid, mille abil keelte rütmitüpoloogiat mõõta. Kuigi ka need mudelid on saanud palju kriitikat (vt nt Arvaniti 2009), on nad siiski üheks võimalikuks mooduseks, kuidas objektiivselt väljendada eri keelte ja ühe keele eri variantide vahelisi tajutavaid rütmilisi erinevusi.

Üks levinumaid mudeleid on paarikaupa muutuvuse indeks (ingl Pairwise Variability Index, lühendatult PVI) (Low \& Grabe et al. 2000; Grabe \& Low 2002), mis kirjeldab teatud akustilise parameetri varieerumist mingi lingvistilise üksuse kaupa, nt vokaali kestuse varieerumist, võrreldes üht vokaaliintervalli järgmise vokaaliintervalliga. PVI-d on rakendatud varasemalt ka eesti keele (Asu \& Nolan 2006; Nolan \& Asu 2009; Kalvik \& Mihkla 2010) ja rootsi keele (Krull 2013) rütmi mõõtmiseks ning eesti keele ja muusika rütmiliste omaduste võrdlemiseks (Raju \& Asu et al. 2010). Ka eestirootsi rütmi kirjeldamiseks kasutasime PVI-d, mille abil mõõtsime kõrvutiste vokaal- ja konsonantüksuste, silpide ja kõnetaktide kestuste suhteid (Asu \& Nolan et al. 2017).

\section{Materjal ja analüüs}

Kuna spontaanses kõnes on rütmiline varieeruvus väga suur, siis kasutati antud uurimuseks loetud kõnet, mis võimaldas ka eestirootsi keelt riigirootsiga paremini võrrelda. Uurimuse materjal pärineb eestirootsi murdetekstide raamatu juurde kuuluvalt kassetilt (Lagman et al. 1990), kust valisime välja kolm loetud lugu kolmelt meeskõnelejalt, sünniaastatega 1919-1920. Nad kõik esindasid Noarootsi murrakut. Iga lugu luges vaid üks keelejuht, ehk siis keelejuhid lugesid erinevaid lugusid. Kahjuks pole teada täpset salvestusaastat, aga võib oletada, et lindistused on tehtud 1980. aastate jooksul, mil keelejuhid olid 60. eluaastates. Kuna samas raamatus on paralleelselt ära toodud ka eestirootsi tekstide rootsikeelsed tõlked, siis oli võimalik neid kasutada riigirootsi keskmurde salvestuste tegemiseks. Kolmelt vanemalt meeskõnelejalt salvestati samade tekstide riigirootsikeelsed vasted, kusjuures iga keelejuht luges vaid ühte teksti. Keelejuhid olid vanuses 63-80 aastat ning pärit Rootsi keskmurde 
alalt (Stockholm, Uppsala). Salvestused tehti 2016. aastal. Nõnda oli võimalik kõrvutada iga loetud eestirootsi teksti selle riigirootsikeelse tõlkega.

Analüüsiks kasutati umbes 90 sekundi pikkust lõiku iga helisalvestuse algusest. Kokku analüüsiti umbes 9 min kõnet. Salvestused segmenteeriti käsitsi programmiga Praat (Boersma \& Weenink 2015), märgendades neljal eri kihil vokaalide intervallid, konsonantide intervallid, fonoloogilised silbid ja kõnetaktid. Iga keelejuhi materjaliks oli keskmiselt 227 vokaalide (V), 248 konsonantide (C), 242 silpide (S) ja 71 kõnetaktide (F) paariviisilist võrdlust. Eri intervallide kestused mõõdeti automaatselt Praat-skriptiga. Keelejuhtide rütmiliste näitajate arvutamiseks kasutati konsonantide puhul nn toorest PVI valemit (vt Asu \& Nolan et al. 2017). Saadud väärtused on tähistatud lühendiga rPVI-C. Vokaalide, silpide ja kõnetaktide puhul kasutati normaliseeritud PVI valemit (vt Low 1998; Asu \& Nolan et al. 2017) ning saadud väärtused on tähistatud vastavalt nPVI-V (vokaalid), nPVI-S (silbid) ja nPVI-F (kõnetaktid). Põhjus, miks konsonantide puhul kasutatakse tavaliselt nn tooreid väärtusi, on see, et sellisel moel on parem tabada keeles leiduvat fonotaktilist varieeruvust.

\section{Tulemused}

Paariviisiline võrdlus kahe rootsi keele dialekti vahel näitas, et ainuke oluline erinevus esines kõnetakti PVI näitajate osas. Samas on andmestik suhteliselt väike ja selleks, et asetada tulemused laiemasse konteksti, on mõttekas võrrelda saadud eestirootsi ja riigirootsi PVI väärtusi teiste keelte, sh eelkõige eesti keele omadega. Joonisel 4 on toodud lisaks kahele uuritavale rootsi keele variandile ka varasematest uurimustest võetud konsonantide ja vokaalide andmed eesti (Asu $\&$ Nolan 2006), inglise (White \& Mattys 2007) ja hispaania keele kohta (White $\&$ Mattys 2007). Kahedimensioonilisel joonisel, mida kasutatakse rütmiliste näitajate visuaalseks kujutamiseks, on x-teljel nn toored rPVI-C väärtused ja y-teljel normaliseeritud nPVI-V väärtused.

Jooniselt 4 on näha, et paindliku konsonantide fonotaktikaga inglise keel, kus vokaalikestuste suurt varieerumist põhjustavad nii fonoloogiline pikkusopositsioon kui ka rõhutute silpide tugev redutseerumine, paigutub kõrge vokaaliindeksi ja kõrge konsonandiindeksi poolest teistest keeltest eraldi. Eesti keel, mis on tunduvalt lihtsama silbistruktuuriga, on ka madalama rPVI-C väärtusega. Võiks oletada, et eesti keele kolme välte süsteem põhjustab suurema variatiivsuse vokaalide osas, andes kõrgema nPVI-V väärtuse. Samas peegeldub kolme vokaalivälte kontrast peamiselt rõhulise silbi vokaali kestuses ning pealegi on vokaalide redutseerumine eesti keeles tunduvalt nõrgem kui inglise keeles; seega kõige tavalisem on siiski kahe lühikese vokaali paariviisiline 
Eva Liina Asu

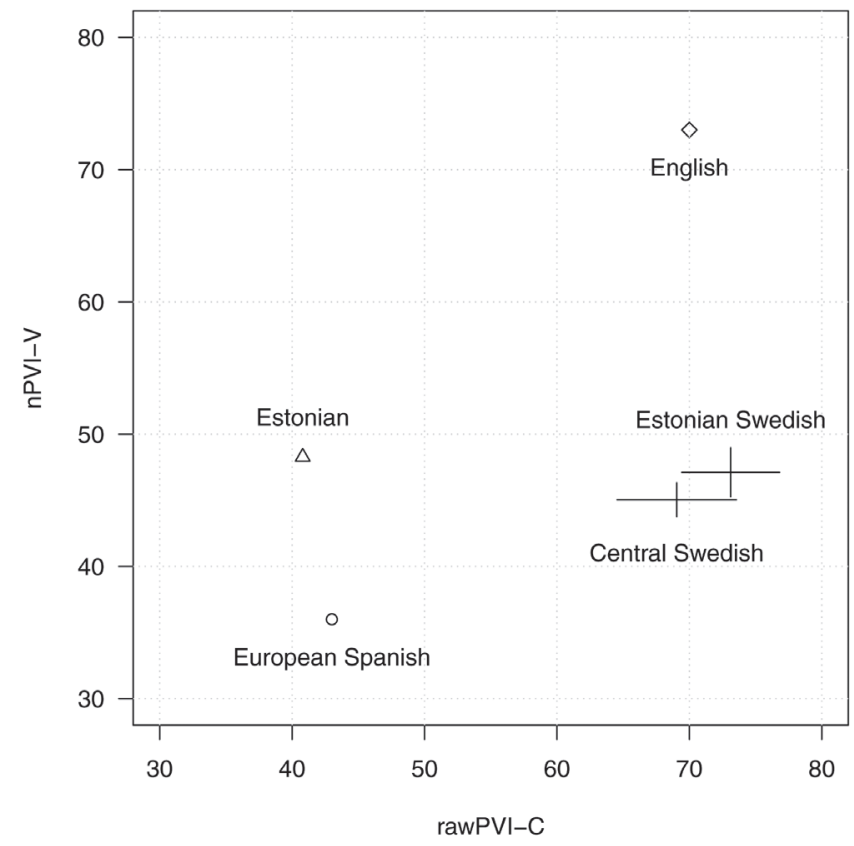

Joonis 4. Eestirootsi ja riigirootsi keskmurde rPVI-C ja nPVI-V (standardhälbega), võrreldes eesti, inglise ja Euroopa hispaania keelega (Asu \& Nolan et al. 2017).

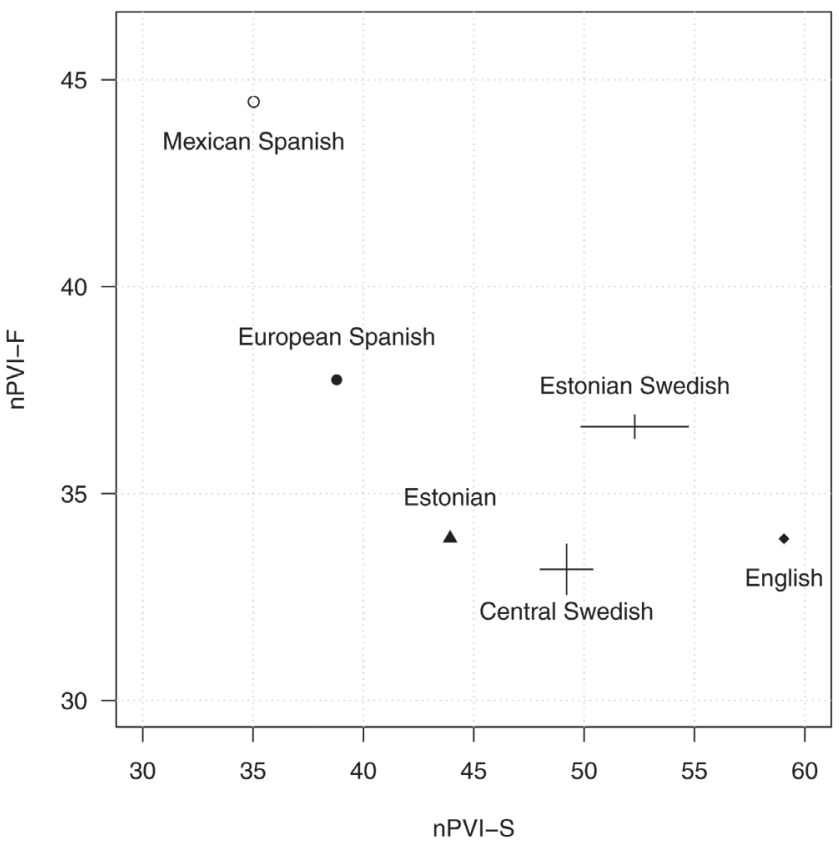

Joonis 5. Eestirootsi ja riigirootsi keskmurde nPVI-S ja nPVI-F (standardhälbega), võrreldes eesti, inglise, Mehhiko ja Euroopa hispaania keelega (Asu \& Nolan et al. 2017). 
võrdlus. Rootsi keel on inglise keelega sarnane oma fonotaktilise tüübi ja kõrge rPVI-C poolest, aga on samal ajal sarnane eesti keelega nPVI-V osas, kuna ka rootsi keeles ei esine nii tugevat vokaalide redutseerumist kui inglise keeles. Kuna eestirootsi ja riigirootsi PVI-väärtused kattuvad suuresti nii vokaalide kui ka konsonantide osas (nende vahel puudub oluline erinevus), siis ei ole vähemalt nende tulemuste põhjal alust arvata, nagu paigutuks eestirootsi keel rütmiliste näitajate poolest riigirootsi ja eesti keele vahele.

Joonisel 5 on x-teljel antud silpide normaliseeritud nPVI-S ja y-teljel kõnetaktide normaliseeritud nPVI-F väärtused. Lisaks kahele uuritavale rootsi keele variandile on varasemast uurimusest (Nolan \& Asu 2009) võetud võrdluseks inglise, eesti, Mehhiko ja Euroopa hispaania keele andmed, mille põhjal autorid väitsid, et silbi- ja kõnetakti tasandil võivad esineda üksteisest sõltumatud rütmilised suundumused. Jooniselt on näha, et eriti selgelt vastanduvad hispaania ja inglise keel, mille põhjuseks on ka siin see, et inglise keeles on tugev vokaalide redutseerumine, vastanduvad lühikesed ja pikad vokaalid ning lubatud on ka keerulisem konsonantide fonotaktika, mida ei ole hispaania keeles. Hispaania keel on silbiajastuskeel ja taktikestused on väga varieeruvad, samas inglise keelele on iseloomulik taktiajastus ja varieeruvad silbikestused. Eesti keel on sarnane hispaania keelele silbikestuste osas ning inglise keelele taktikestuste osas ja seda võiks seega ühtaegu lugeda nii silbiajastuskeeleks kui ka takti- ehk rõhuajastuskeeleks (Nolan \& Asu 2009).

Nii eestirootsi kui ka riigirootsi murre paiknevad oma silbiväärtuste osas eesti ja inglise keele vahepeal. Kahe dialekti nPVI-S väärtustes polnud olulist erinevust. Ainuke oluline erinevus oli nPVI-F osas. Samas tuleks seda statistilist olulisust tõlgendada ülima ettevaatusega, kuna keelejuhtide arv ja materjali hulk on selles uurimuses suhteliselt väikesed ning küsimusi tekitab ka kõnetakti mõiste defineerimine, mis võrreldes teiste mõõdetud üksustega on problemaatilisem ja keelespetsiifilisem.

\section{Arutelu}

Vastupidiselt algsele hüpoteesile ei paigutu eestirootsi oma rütmiliste kestusnäitajate poolest riigirootsi ja eesti keele vahele. Enamiku näitajate osas rühmitub eestirootsi kokku riigirootsiga, v.a kõnetaktide (nPVI-F) osas, kus eestirootsi keel erineb eesti keelest veelgi rohkem kui riigirootsi keel. Tekib küsimus, et kui eestirootsi kõnetakt on vähem regulaarne, siis miks. Kui kestusnäitajad viitavad suhteliselt väiksele eestirootsi ja riigirootsi rütmi erinevusele, siis mille alusel võiks öelda, et eestirootsi on rütmiliselt erinev (nt Lagman 1979)? 
Nagu teada, on Skandinaavia keeltes silbis komplementaarsed kestused, s.t pikale vokaalile järgneb alati lühike konsonant (CV:C) või vastupidi (CVC:). Eestirootsi keeles on vähemalt osaliselt säilinud vanemad vokaali ja konsonandi kestuste vahekorrad silbituuma vokaalis ja kooda konsonandis: pikale vokaalile või diftongile võib järgneda konsonantühend (Danell 1905-1934), nt riigirootsi keskmurre [tysk] tysk 'saksa', [hœst] höst 'sügis'; eestirootsi [ti:sk], [he:st]. Lubatud on ka lühike vokaal lühikese konsonandi ees, nt smöre [smœrc] 'võidma', kide [kœte] 'liha'. Samas esineb selliseid sõnu antud tekstides üsna vähe ja neil ei saa olla tulemusele kuigi suur mõju. Pigem tuleb olla ettevaatlik nPVI-F tõlgendamisel, sest mõlema murde materjal koosnes ainult kolme keelejuhi kõnest ning ainult 44-91 kõnetakti-intervallist keelejuhi kohta (vrd 190-257 silbi-intervalli nPVI-S arvutamiseks). Seega on eestirootsi murre rütmiliste näitajate poolest väga sarnane riigirootsi murdega, mis tegelikult polegi nii üllatav, sest fonoloogiliselt (sh segmendid, fonotaktika) on tegemist ikkagi rootsi keelega.

Kui ka suurema materjali põhjal peaks selguma, et eestirootsi keeles ongi kõrgem nPVI-F kui riigirootsi keeles, siis tundub see ikkagi rääkivat vastu Lagmani (1979) tähelepanekule ühtlasemast prominentsete silpide esinemisest eestirootsi keeles, kuna suurem variatiivsus prominentsete silpide vaheliste intervallide kestuses viitab pigem prominentsuste ebaregulaarsemale jaotumisele. Seetõttu jäävad osutatud tajutud rütmilised erinevused antud juhul seletuseta.

Samas ei väljendu rütm ainult kestusmustrites (nt Nolan \& Asu 2009), vaid ka põhitoonis, intensiivsuses ja vokaalikvaliteedis (Low 1998). Rütmi arvutamise mudeleid on vahel rakendatud lisaks kestusele ka intensiivsuse mõõtmiseks (nt Cichocki \& Selouani et al. 2014) ja eri kõnelejate, mitte ainult piirkondlike variantide iseloomustamiseks (nt He \& Dellwo 2014). Kuigi kindlasti võiks eestirootsi ja riigirootsi rütmi võrdlemiseks mõõta ka variatiivsust intensiivsuses, on siiski tõenäolisem, et tajutud rütmiline erinevus, millele Lagman (1979) viitab, tuleneb pigem nende kahe rootsi murde intonatsioonilisest erinevusest. Nagu näitas ka uurimus sõnatoonidest (Schötz \& Asu 2015), ei esine eestirootsi keeles tonaalset opositsiooni, mis kindlasti mõjutab eestirootsi kõne prosoodilist tajupilti. Kahtlemata pakuks edasine eestirootsi murde intonatsiooni analüüs siinkohal mõningaid vastuseid.

\section{Kokkuvõte}

Ajendatuna väitest, et eestirootsi keel erineb rütmiliselt riigirootsi keelest ning arvestades eesti keele mõjudega, oletasime, et eestirootsi paigutub rütmilis- 
te näitajate osas rootsi ja eesti keele vahele. Analüüsisime kolme eestirootsi ja kolme riigirootsi keelejuhi loetud kõnet ning võrdluseks eesti ning muude keeltega kasutasime tulemusi varasematest uurimusest (Nolan \& Asu 2009; White \& Mattys 2007). Rütmi kirjeldamiseks rakendati paarikaupa muutuvuse indeksit (PVI), mille abil mõõdeti kõrvutiste vokaal- ja konsonantüksuste, silpide ja kõnetaktide kestuste suhteid. Tulemused näitasid, et eestirootsi keele rütm on oma kestusnäitajate poolest siiski väga sarnane riigirootsi keele rütmiga. Need kaks rootsi murret paigutuvad lähestikku vokaali-, konsonandi-ja silbiväärtuste osas; ainuke vihje võimalikule erinevusele leidus kõnetaktide osas, aga seegi on pigem vastuolus algse hüpoteesiga. Sellest hoolimata ei saa antud uurimuse põhjal väita, et eestirootsi ja riigirootsi keel ei ole rütmiliselt erinevad, kuna kõne rütmi ei peegelda ainult kestus.

\section{Lõpetuseks}

Eestirootsi murre on huvipakkuv mitmel põhjusel. Selles on säilinud paljud arhailised jooned, mis on kadunud peaaegu kõikidest muudest rootsi murretest. Lisaks on tunda eesti keele mõjutusi, mis avalduvad muuhulgas ka hääldusjoontes. Käesolevas artiklis olid lähema vaatluse all eestirootsi keele prosoodia aspektid - sõnatoonid ja rütm.

\section{Tänusõnad}

Artikkel on seotud Rootsi Teadusfondi projektiga "Estlandssvenskans språkstruktur" (ESST) (Vetenskapsrådet, 2012-907) ja Eesti Teadusagentuuri institutsionaalse uurimisprojektiga IUT 2-37. 


\section{Kirjandus}

Andréasson, Maia 2016. Subject placement in Estonian Swedish. Vikner, Sten \& Jørgensen, Henrik \& van Gelderen, Elly (toim). Let us have articles betwixt us. Papers in Historical and Comparative Linguistics in Honour of Johanna L. Wood. Aarhus: Aarhus Unversity, lk 83-98.

Ariste, Paul 1931. Mis on Loode-Eesti murrete hääldamises rootsipärane? Eesti Keel. Akadeemilise Emakeele Seltsi ajakiri 3-4. Tartu, lk 73-82.

Ariste, Paul 1933. Eesti-rootsi laensõnad eesti keeles. Acta et Commentationes Universitatis Tartuensis (Dorpatensis) 29 (3). Tartu.

Ariste, Paul 1981. Keelekontaktid: eesti keele kontakte teiste keeltega. Tallinn: Valgus.

Arvaniti, Amalia 2009. Rhythm, timing and the timing of rhythm. Phonetica 66, lk 46-63 (doi: 10.1159/000208930).

Asu, Eva Liina \& Ewald, Otto \& Schötz, Susanne 2015. The realisation of sj- and tjsounds in Estonian Swedish: some preliminary results. Proceedings from Fonetik 2015: Lund, June 8-10, 2015. Working papers in Linguistics; 55. Lund: Lund University, lk 23-26 (http://person2.sol.lu.se/SusanneSchotz/Publications_files/2015/WP55_Asu. pdf - 22. november 2017).

Asu, Eva Liina \& Lippus, Pärtel \& Pajusalu, Karl \& Teras, Pire 2016. Eesti keele hääldus. Tartu: Tartu Ülikooli Kirjastus.

Asu, Eva Liina \& Nolan, Francis 2006. Estonian and English rhythm: a two-dimensional quantification based on syllables and feet. Proceedings of Speech Prosody 2006. Dresden: TUDpress, lk 249-252.

Asu, Eva Liina \& Nolan, Francis \& Schötz, Susanne 2015. A comparative study of Estonian Swedish voiceless laterals: are voiceless approximants fricatives? Proceedings of the 18th International Congress of Phonetic Sciences, 10-14 August 2015, Glasgow (paper 0077).

Asu, Eva Liina \& Nolan, Francis \& Schötz, Susanne 2017. Rhythm in Estonian Swedish. Abrahamsen, Jardar Eggesbø \& Koreman, Jacques \& van Dommelen, Wim A. (toim). Nordic Prosody. Proceedings of the XIIth Conference, Trondheim 2016 (73-82). Frankfurt am Main: Peter Lang GMBH (doi: 10.3726/b11152).

Boersma, Paul \& Weenink, David 2015. Praat: Doing Phonetics by Computer [Computer program]. Versions 5.4.01-6.0.05 (http://www.praat.org/ - 22. november 2017).

Bruce, Gösta 1998. Allmän och svensk prosodi. Praktisk Lingvistik 16. Lund: Institutionen för Lingvistik, Lunds Universitet.

Bruce, Gösta 2007. Components of a prosodic typology of Swedish intonation. Riad, Tomas \& Gussenhoven, Carlos (toim). Tones and Tunes 1 . Typological Studies in Word and Sentence Prosody. Berlin: Mouton de Gruyter, lk 113-146 (doi: 10.1515/9783110207569.113).

Bye, Patrik 2004. Evolutionary typology and Scandinavian pitch accent. Kluwer Academic Publishers. 
Cichocki, Wladyslaw \& Selouani, Sid-Ahmed \& Perreault, Yves 2014. Measuring rhythm in dialects of New Brunswick French: is there a role for intensity? Canadian Acoustics 43 (3), lk 90-91.

Danell, Gideon 1905-1934. Nuckömålet I-III. Stockholm.

Eliasson, Stig 2008. Language contact outside Scandinavia I: In the Baltic. Bandle, Oskar \& Braunmüller, Kurt \& Jahr, Ernst Hakon \& Karker, Allan \& Naumann, Hans-Peter \& Teleman, Ulf \& Elmevik, Lennart \& Widmark, Gun (toim). The Nordic Languages 2. Berlin: de Gruyter, lk 2048-2057.

Ewald, Otto 2016. The Estonian Swedish diphthongs / ai au oi ui /:Acoustic characteristics and cross-dialectal variation. Masteruppsats. Lund: Språk- och litteraturcentrum, Lunds universitet.

Ewald, Otto \& Asu, Eva Liina \& Schötz, Susanne 2017. The formant dynamics of long close vowels in three varieties of Swedish. Proceedings of Interspeech 2017: Interspeech 2017, 20-24 August 2017, Stockholm. Stockholm: International Speech Communication Association (http://www.isca-speech.org/archive/Interspeech_2017/pdfs/1134.PDF 22. november 2017).

Gårding, Eva 1977. The Scandinavian word accents. Lund: Gleerup.

Grabe, Esther \& Low, Ee Ling 2002. Durational Variability in Speech and the Rhythm Class Hypothesis. Gussenhoven, Carlos \& Warner, Natasha (toim). Laboratory Phonology 7. Berlin: Mouton de Gruyter, lk 515-546.

Haugen, Einar 1976. The Scandinavian languages: An introduction to their history. London: Faber \& Faber.

He, Lei \& Dellwo, Volker 2014. Speaker idiosyncratic variability of intensity across syllables. Proceedings of Interspeech 2014, Singapore, lk 233-237 (doi: 10.5167/uzh103024).

Juhkam, Evi 1983. Rootsipärane objekt eesti murretes. Keel ja Kirjandus 3, lk 122-125.

Juhkam, Evi 1992. Eestirootslastest. Keel ja Kirjandus 7, lk 394-402.

Juhkam, Evi 1998. Eesti-rootsi murdekontaktid. Magistritöö. TPÜ (käsikiri Eesti Keele Instituudi murdesektoris). Tallinn.

Juhkam, Evi 2000. Eestirootsi tõlkelaenud eesti murretes. Jüri Viikberg (toim). Inter dialectos nominaque. Pühendusteos Mari Mustale 11. novembril 2000. Eesti Keele Instituudi toimetised 7. Tallinn: Eesti Keele Sihtasutus, lk 53-72.

Juhkam, Evi 2009. Eestirootsi refleksiivverbi mõjust eesti murrete verbikasutusele. Kallasma, Marja \& Oja, Vilja (toim). Kodukeel ja keele kodu. Pühendusteos Helmi Neetarile 75. sünnipäevaks 29. jaanuaril 2009. Tallinn, lk 57-69.

Kalvik, Mari-Liis \& Mihkla, Meelis 2010. Modelling the temporal structure of Estonian speech. Skadina, Inguna \& Vasiljevs, Andrejs (toim). Human Language Technologies. The Baltic Perspective. Proceedings of the Fourth International Conference, Baltic HLT 2010. Riga, Latvia, October 7-8, 2010. Frontiers of Artifical Intelligence and Applications; 219. Amsterdam: IOS Press, 53-60 (doi: 10.13140/2.1.5076.4807). 
Krull, Diana 2013. Rhythmic variability and Swedish-Estonian language contact. Asu, Eva Liina \& Lippus, Pärtel (toim). Nordic Prosody. Proceedings of the XIth Conference, Tartu 2012. Frankfurt am Main: Peter Lang Verlag, lk 197-204.

Lagman, Edvin (toim) 1979. En bok om Estlands svenskar. Estlandssvenskarnas språkförhållanden. 3A. Stockholm: Kulturföreningen Svenska Odlingens Vänner.

Lagman, Edvin \& Aman, Viktor \& Nyman, Elmar (toim) 1990. En bok om Estlands svenskar. Estlandssvenskar berättar: dialekttexter med översättning och kommentar. $3 B$. Kristianstad: Kulturföreningen Svenska Odlingens Vänner.

Liberman, Anatoly 1982. Germanic accentology. The Scandinavian Languages 1. University of Minnesota: University of Minnesota Press.

Lindström, Jonathan 2015. Biskopen och korståget 1206: om krig, kolonisation och Guds man i Norden. Stockholm: Norstedt.

Low, Ee Ling 1998. Prosodic Prominence in Singapore English. Doctoral dissertation, University of Cambridge.

Low, Ee Ling \& Grabe, Esther \& Nolan, Francis 2000. Quantitative characterisations of speech rhythm: 'Syllable-timing' in Singapore English. Language and Speech 43, lk 377-401 (doi: 10.1177/00238309000430040301).

Markus, Felicia 2004. Living on another shore: early Scandinavian settlement on the North-Western Estonian coast. Occasional papers in archaeology. Uppsala: Institutionen för arkeologi och antik historia.

Nolan, Francis \& Asu, Eva Liina 2009. The Pairwise Variability Index and coexisting rhythms in language. Phonetica 66, lk 64-77 (doi: 10.1159/000208931).

Pike, Kenneth L. 1945. The intonation of American English. Ann Arbor: University of Michigan Press.

Raju, Marju \& Asu, Eva Liina \& Ross, Jaan 2010. Comparison of rhythm in musical scores and performances as measured with the Pairwise Variability Index. Musicae Scientiae 14 (1), lk 51-71 (doi: 10.1177/102986491001400102).

Riad, Tomas 2006. Scandinavian accent typology. Sprachtypologie und Universalienforschung 59 (1), lk 36-55 (http://www.su.se/polopoly_fs/1.29915.1320939951!/RiadStuf2006. pdf - 23. november 2017).

Rosenkvist, Henrik 2015. Negative concord in four varieties of Swedish. Arkiv för nordisk filologi 130, lk 139-166 (https://www.researchgate.net/publication/292059808_Negative_ Concord_in_Four_Varieties_of_Swedish - 23. november 2017).

Rosenkvist, Henrik 2016. Negationer i estlandssvenska. Andersson, Daniel \& Haugen, Susanne \& Westum, Asbjørg (toim). Studier i svensk språkhistoria 13. Historia och språkhistoria, lk 199-210. Umeå: Institutionen för språkstudier.

Schötz, Susanne \& Asu, Eva Liina 2013. An acoustic study of accentuation in Estonian Swedish compounds. Asu, Eva Liina \& Lippus, Pärtel (toim). Nordic Prosody: Proceedings of the XIth Conference, Tartu 2012. Frankfurt am Main: Peter Lang, lk 343-352 (doi: 10.3726/978-3-653-03047-1). 
Schötz, Susanne \& Asu, Eva Liina 2015. In search of word accents in Estonian Swedish. Proceedings of the 18th International Congress of Phonetic Sciences, 10-14 August 2015, Glasgow (paper 0314, https://www.researchgate.net/publication/281610567_IN_ SEARCH_OF_WORD_ACCENTS_IN_ESTONIAN_SWEDISH - 23. november 2017).

Schötz, Susanne \& Bruce, Gösta \& Segerup, My \& Beskow, Jonas \& Gustafson, Joakim \& Granström, Björn 2012. Regional varieties of Swedish: Models and synthesis. Niebuhr, Oliver (toim). Prosodies - context, function, communication. Berlin/New York: de Gruyter, lk 119-134.

Schötz, Susanne \& Nolan, Francis \& Asu, Eva Liina 2014. An acoustic study of the Estonian Swedish lateral [1]. Heldner, Mattias (toim). Proceedings from FONETIK 2014, Stockholm, June 9-11, 2014. PERILUS XXIV. Stockholm: Stockholm University, lk 23-28 (http://portal.research.lu.se/ws/files/4308655/4882274.pdf-23. november 2017).

Selenius, Ebba 1972. Västnyländsk ordaccent. Studier i nordisk filologi 59. Helsingfors: Centraltryckeriet.

Selenius, Ebba 1978. Studies in the development of the 2-accent system in Finland Swedish. Gårding, Eva \& Bruce, Gösta \& Bannert, Robert (toim). Nordic Prosody. Papers from a symposium. Lund: Lund University, lk 229-236.

Svärd, Nina 2001. Word accents in the Närpes dialect: Is there really only one accent? Proceedings of Fonetik. Working Papers 49. Department of Linguistics, Lund University, lk 160-163.

Tiberg, Nils 1962. Estlandssvenska språkdrag. Uppsala: Lundequistska bokhandeln.

White, Laurence \& Mattys, Sven L. 2007. Calibrating rhythm: first language and second language studies. Journal of Phonetics 35, lk 501-522 (doi: 10.1016/j.wocn.2007.02.003).

\title{
Summary
}

\section{Some features of Estonian Swedish prosody}

\author{
Eva Liina Asu \\ Senior Research Fellow in Phonetics \\ Institute of Estonian and General Linguistics, University of Tartu \\ eva.liina.asu-garcia@ut.ee
}

Keywords: prosody, word tones, rhythm, Swedish, varieties of Estonian Swedish

Estonian Swedish was traditionally spoken on the western coast and islands of Estonia. Nowadays, it is almost extinct, surviving only as a language of occasional communication of some elderly speakers who emigrated from Estonia to Sweden as children during World War II. Estonian Swedish is a typologically interesting variety of Swedish, as it retains a number of archaic segmental features (e.g. Old Scandinavian diphthongs) and has been influenced by its most important contact language, Estonian. 
The article addresses such aspects of Estonian Swedish prosody as word accents and rhythm. An investigation of the realisation of tonal accents in disyllabic words showed that Estonian Swedish (like Finland Swedish) lacks the lexical pitch accent distinction that is characteristic of Standard Swedish. A comparative study of rhythm in read speech explored the hypothesis that Estonian Swedish may be intermediate between Swedish (as represented by Central Swedish from the Stockholm area) and Estonian. The results showed, however, that the durational values of Estonian Swedish rhythm are very similar to those of Central Swedish. 